\title{
MEMBRANAS DE D-PTFE CYTOPLAST® EM REGENERAÇÃO ÓSSEA GUIADA NA IMPLANTODONTIA
}

\section{ARTIGO DE REVISÃO}

CARNEIRO, Renato Brandi Pereira ${ }^{1}$

KFOURI, Flávio de Ávila ${ }^{2}$

CARNEIRO, Renato Brandi Pereira. KFOURI, Flávio de Ávila. Membranas de D-Ptfe Cytoplast ${ }^{\circledR}$ em regeneração óssea guiada na implantodontia. Revista Científica Multidisciplinar Núcleo do Conhecimento. Ano 05, Ed. 09, Vol. 05, pp. 108-135. Setembro de 2020. ISSN: 2448-0959, Link de acesso: https://www.nucleodoconhecimento.com.br/odontologia/regeneracao-ossea

\section{RESUMO}

O aumento ósseo vertical de rebordo alveolar é importante para obtenção de bons resultados em reabilitações com próteses sobre implantes. Esta Revisão Bibliográfica buscou artigos que tratem de aumentos ósseos de rebordos alveolares utilizando-se membranas Cytoplast $\AA$, buscando avaliar a resistência à penetração bacteriana e capacidade de criação e manutenção de espaço. Para isto, foi feita revisão da literatura nas plataformas de busca Pubmed e Google scholar. As pesquisas analisadas encontraram resultados semelhantes entre a membrana de d-PTFE, malhas de titânio e membranas de e-PTFE, tanto em ganho ósseo, quanto em qualidade óssea. A capacidade de manutenção de espaço ficou evidente nos artigos em que foi utilizada a membrana reforçada com titânio. A membrana de d-PTFE apresentou uma capacidade maior de exposição ao meio bucal sem comprometer o material de enxerto. Os autores pesquisados neste estudo descobriram que

\footnotetext{
${ }^{1}$ Graduação em Odontologia.
}

2 Orientador. Doutorado em Ciências. Mestrado profissional em Odontologia. Especialização em Implantodontia. Graduação em Odontologia. 
membranas de d-PTFE reforçadas com titânio para aumentos ósseos de rebordos alveolares são viáveis e permitem um certo período de exposição ao meio bucal sem que haja contaminação do enxerto. São necessários mais estudos com a membrana de d-PTFE Cytoplast ${ }^{\circledR}$ que explorem suas características com procedimentos de aumento ósseo vertical.

Palavras-chaves: Membranas artificiais, regeneração tecidual guiada, regeneração óssea.

\section{INTRODUÇÃO}

A implantodontia revolucionou a odontologia possibilitando o restabelecimento da ausência do órgão dental, artificialmente. Muitas vezes, o Implantodontista, ao planejar a reabilitação com implantes se depara com pouca altura ou largura do rebordo alveolar remanescente, impossibilitando o ideal posicionamento dos implantes de acordo com o planejamento retrógrado executado e para dar continuidade ao planejamento pode se utilizar da técnica de regeneração óssea guiada (ROG) para obter um aumento ósseo na região que receberá os implantes.

Os 4 princípios biológicos necessários ao sucesso em regeneração óssea guiada (isto é, PAEE) são: "(i) fechamento primário da ferida; (ii) angiogênese para fornecer suprimento sanguíneo necessário; (iii) criação e manutenção de espaço e (iv) estabilidade da ferida" (WANG; BOYAPATI, 2006, p. 8-11)

Urban et al. (2016) descreveram a técnica de retalho onde existe liberação de periósteo feita com incisões periosteais e radiais e avanço do retalho com empurrões no sentido coronal aumentando significativamente superfície do retalho, permitindo o preenchimento com biomaterial e obtenção do fechamento primário da ferida.

Pesquisadores observaram que se uma membrana não é exposta e se mantém sem eventos por 6 a 9 meses, é obtida a completa formação óssea e que quando existe insucesso, na maioria das vezes foi por causa de exposição da membrana e consequente contaminação do enxerto. (CUCCHI et al., 2017) 
Urban et al., (2017) ressaltaram que a membrana deve ser fixa com parafusos por lingual e vestibular para que fique imóvel durante o processo de ROG vertical.

Pesquisadores descreveram as 5 características de uma membrana para Regeneração Óssea Guiada vertical: “(i) Biocompatibilidade; (ii) Criação e manutenção de espaço; (iii) Oclusividade e permeabilidade seletiva; (iv) Integração de tecidos; (v) Capacidade de gerenciamento clínico." (NAUNG; SHEHATA; VAN SICKELS, 2019, p. 2)

Muitas membranas foram propostas para ROG, tanto absorvíveis quanto não absorvíveis e podem ser de colágeno, placenta humana, pericárdio humano, tendão humano, feitas de ácido poliglicólico, ácido polilático, politetrafluoretileno expandido ou denso e malha de Titânio. (NAUNG; SHEHATA; VAN SICKELS, 2019)

Lee et al. (2020) analisou os efeitos da L-PRF como uma membrana na ROG horizontal em alvéolos criados em cães, depois de 4 semanas comparou os resultados do L-PRF com outras membranas absorvíveis e não absorvíveis. Após mais 4 semanas de cicatrização óssea, a nova quantidade óssea para cada grupo foi medida por microscopia e tomografia micro computadorizada verificando que o L-PRF desempenha um papel efetivo como membrana para o aumento lateral da crista.

Salomão et al. (2010) relatou dois casos usando uma barreira de polipropileno (Bone Heal® - INP, São Paulo) sem a associação de nenhum material de preenchimento (enxerto ou implante de biomateriais), foi usada a fim de manter aprisionado o coágulo com o objetivo de recuperar arquitetura do rebordo alveolar e promover neoformação óssea, para que permitisse a instalação adequada de um implante osteointegrável. Antes de colocar a barreira, o alvéolo foi estimulado para ser totalmente preenchido com sangue.

As membranas não absorvíveis, quando expostas têm maior índice de infecção que as absorvíveis. A membrana de PTFE denso impede a passagem de bactérias mesmo quando exposta utilizando bochechos de clorexidina $(0,12 \%)$ e aplicando gel de clorexidina (1\%). (GHENSI et al., 2017) 
A patente US7296998B2 de 2007 descreve uma folha de material polimérico de politetrafluoretileno (PTFE) hidrofílico, substancialmente não expandido, possui cavidades que têm uma profundidade menor que a espessura da folha. (CHADDICK; BARTEE, 2007).

\section{PROPOSIÇÃO}

Objetivo desta pesquisa é revisar a literatura mais recente sobre a utilização da membrana de d-PTFE (Cytoplast $\circledast$ Osteogenics Biomedical, Texas) em regeneração óssea guiada na implantodontia, abordando sua resistência a penetração bacteriana e sua capacidade de manutenção de espaço.

\section{REVISÃO DA LITERATURA}

Barber et al. (2007) relatou dois casos de ROG com instalação simultânea de implante e cobertura com membrana de d-PTFE (Cytoplast ${ }^{\circledR}$ Regentex GBR-200 ou TXT-200 Osteogenics Biomedical, Lubbock, TX) sem reforço. Relatou uma técnica de ROG onde deixou a membrana exposta sem expor as bordas por 6 semanas em um caso de exodontia e implante imediato de $1^{\circ}$ pré-molar superior. No segundo relato de caso, um acidentado por trauma, manteve a membrana Cytoplast ${ }^{\circledR}$ por 4 semanas, retirando com facilidade e obtendo uma camada consistente de tecido osteóide na colocação dos implantes de uma região de maxila anterior 5 elementos sem intercorrências e ocorreu migração epitelial sobre o tecido osteóide na semana 6 , incrementando a largura do tecido queratinizado antes da injúria sofrida. Barber et al. (2007) ressaltou que "a densidade da membrana d-PTFE impede a colonização da flora hospedeira e evita a contaminação do biomaterial abaixo da membrana". Ele percebeu também que com essa técnica a mucosa queratinizada, cicatriza por segunda intenção, terminando seu fechamento com uma maior área. Concluiu que como o fechamento primário sobre a membrana d-PTFE não é necessário, o cirurgião pode tratar grandes defeitos, preservar a papila interdental e preservar toda a largura da mucosa queratinizada, sem a preocupação de contaminação ou infecção bacteriana e também que o uso de membrana de d-PTFE Cytoplast ${ }^{\circledR}$ é a opção ideal de tratamento para Alvéolos de exodontias sem fechamento primário da ferida, devido a simplicidade em sua 
colocação e remoção sem comprometer a qualidade da regeneração. (BARBER et al., 2007)

Hoffmann et al. (2008) investigou a regeneração clínica de alvéolos de exodontias, usando membranas de d-PTFE, sem o uso de material de enxerto, para isso, avaliou 276 alvéolos de exodontias em 276 indivíduos (151 homens e 125 mulheres; idade média, 50,2 anos; faixa etária: 24 a 73 anos). Mensurou a porcentagem de ganho ósseo obtida após ROG com uso de membrana Cytoplast ${ }^{\circledR}$, sem uso de fechamento primário da ferida. Antes da extração ele confeccionava um guia personalizado que podia ser fixado aos dentes adjacentes com cinco orifícios onde através de sonda periodontal pôde obter medidas de profundidade do alvéolo após a exodontia. Após a extração, os retalhos foram elevados e uma membrana de d-PTFE (Cytoplast ${ }^{\circledR}$ Regentex GBR-200) sem reforço de titânio, foi colocada sobre a extração local. Os retalhos foram reposicionados e suturados no lugar. $O$ fechamento primário não foi obtido sobre as membranas. As membranas foram removidas após 4 meses. As junções cemento-esmalte dos dentes adjacentes foram utilizadas como pontos de referência. As medidas foram realizadas com uso do guia, após a extração e 12 meses após a cirurgia nas mesmas áreas, as variáveis descritas no nível ósseo foram relatadas individualmente para todos os casos revisados e também nos grupos por fatores de interesse investigados: alvéolo único ou lado a lado, mandíbula, e região, o ganho ósseo em defeitos verticais foram expressos em médias $E$ ainda realizou 10 biópsias de tecidos duros 12 meses após a preservação do alvéolo durante a colocação do implante, obtendo como resultado, ganho ósseo significativo das amostras do núcleo ósseo, regeneração significativa do volume dos alvéolos que pôde ser observado por avaliação histológica, indicando que o tecido recém-formado nos locais de extração era principalmente osso. Não encontrou nenhuma influência de sexo, tabagismo <=10 cigarros, idade ou nível ósseo clínico sobre a porcentagem de ganho ósseo. Concluiu que o uso de membrana de d-PTFE Cytoplast® conduziu à preservação do tecido mole e duro em locais de exodontias.

Com Relação aos Ensaios Clínicos Randomizados, segundo a declaração CONSORT de 2010 (SCHULZ; ALTMAN et al., 2010): 
Quando adequadamente projetados, conduzidos e relatados, representam o padrão-ouro em avaliação intervenções de saúde. Para avaliar com precisão um estudo, os leitores de um relatório publicado precisam de informações completas, claras e transparentes sobre seu método, tecnologia e descobertas. O Estado do CONSORT 2010 portanto, atende aos critérios mínimos, embora esse não deve impedir os autores de incluir outras informações se eles consideram importantes.(SCHULZ; ALTMAN, et al., 2010, p. 698)

Urban et al. (2014) avaliaram o uso da membrana de d-PTFE (Cytoplast ® Ti-250) reforçada com titânio em combinação com uma mistura de osso autógeno e BioOss $\AA$, para isso fizeram vinte aumentos ósseos verticais de rebordo alveolar utilizando membrana d-PTFE reforçada com titânio Cytoplast $\AA^{\circledR}$ Ti-250 Osteogenics Biomedical, fixada com tachas de osso de titânio Master Pin Control $\AA^{\circ}$, Messinger e/ou parafusos tenda Pro-Fix Tentin Screw ${ }^{\circledR}$, Osteogenics Biomedical e uma mistura de 1:1 de osso autólogo e Biooss $\AA$ e fechando sem tensão com sutura dupla de colchoeiro horizontal e simples, não houve exposição da membrana. Obtiveram como resultado uma média de ganho ósseo de 5,45 mm e1,93 de desvio padrão. A histologia revelou que as partículas Biooss $₫$ "foram conectadas a uma densa rede de osso recém-formado, em todas as amostras, o espaço medular foi bem perfundido com vasos sanguíneos e nenhuma resposta inflamatória ou reação de corpo estranho foi observada." (URBAN et al., 2017). Concluíram que a utilização da membrana Cytoplast® Ti-200 é viável para técnica de aumento de rebordo alveolar vertical com osso autólogo mais Biooss $\AA$ 1:1 e fechamento da ferida sem tensão sem exposição da membrana.

Ronda et al. (2014) fizeram um estudo prospectivo e randomizado controlado projetado para testar as membranas de d-PTFE Cytoplast@Ti-250 e de e-PTFE Goretex ${ }^{\circledR}$, ambas reforçadas com titânio associadas a osso autólogo e aloencherto em grânulos mineralizado (Puros ${ }^{\circledR}$, Zimmer Dental, Carlsbad CA, USA), 1:1 em 23 pacientes que necessitaram de aumento ósseo vertical do rebordo alveolar com procedimentos de ROG para colocação de implantes em mandíbulas posteriores atróficas (altura óssea disponível $<7 \mathrm{~mm}$ ). Os implantes foram colocados no nível planejado deixando as expiras aparentes que foram cobertas pelo biomaterial de enxerto, e só então era randomizada qual membrana que o cirurgião utilizou. Foi feito fechamento de ferida sem tensão com dupla sutura. Os resultados demonstraram que 
não houve diferença significante entre as porcentagens de ganho ósseo dos dois grupos. As duas biópsias coletadas no procedimento de remoção das membranas apresentaram duas regiões: "uma de osso lamelar bem organizado e outra com pequenas lacunas hospedando osteócitos e uma parte coronal caracterizada principalmente por tecido ósseo composto com presença de trabéculas pequenas e imaturas." (RONDA et al., 2014, p. 863). Concluíram que, as membranas d-PTFE e ePTFE mostraram resultados clínicos idênticos no tratamento de defeitos ósseos verticais ao redor dos implantes, usando essa técnica e que o procedimento de remoção da membrana foi mais fácil de ser realizado no grupo d-PTFE do que no grupo e-PTFE, atribuído ás porosidades da camada externa que aderem ao tecido conjuntivo, Ronda et al., (2014) ressaltou que "embora a presença de uma porção porosa de uma das membranas parecer desempenhar um papel importante na estabilização de dispositivo, favorecendo sua integração com o tecido mole, não pareceu ser essencial na obtenção de regeneração óssea."

Maridati et al., (2016) propuseram e testaram o manejo de exposições da membrana de d-PTFE Cytoplast ${ }^{\circledR}$ para obtenção de sucesso clínico final, relatou um caso, em um procedimento de aumento ósseo vertical de rebordo alveolar, paciente de 63 anos onde ele instalou um implante de $3,4 \varnothing \times 11 \mathrm{~mm}$, deixando algumas espiras e a lateral lisa do implante expostos, preencheu com Biooss $\AA$ e adaptou a membrana reforçada com titânio Cytoplast ${ }^{\circledR}$ fixando com 4 pinos, acompanhou uma exposição da membrana de d-PTFE, mesmo tendo feito fechamento da ferida sem tensão. Houve exposição $>3 \mathrm{~mm}$ sem sinal de infecção no $14^{\circ}$ dia. A membrana foi deixada no lugar por mais duas semanas. $\mathrm{Na} 4^{\circ}$ semana a membrana removida e posicionado um enxerto de conjuntivo do palato para proteger o enxerto ósseo no $7^{\circ}$ mês foi instalado o abutman e coroa parafusada com sucesso. Baseando-se em que devido a membrana Cytoplast possuir alta densidade e poros menores que 02-03 micrômetros e por já ter sido testada em alvéolos pós exodontia antes, sem fechamento primário da ferida sem tensão, neste estudo obteve bons resultados acompanhando a exposição da membrana> $3 \mathrm{~mm}$ e posteriormente enxertando tecido conjuntivo ao remover a membrana. Concluíram que acompanhar a exposição da membrana sem 
removê-la por 4 semanas garante a manutenção de espaço apropriada, devido à resistência da membrana à contaminação bacteriana.

Ghensi et al. (2017) demonstraram que é possível manejar exposições da membrana de d-PTFE Cytoplast $\circledast$ em seu relato de caso, acompanharam uma exposição $<3 \mathrm{~mm}$ de membrana de d-PTFE reforçada com enxerto autógeno e BioOss ${ }^{\circledR}$ 1:1 Mais parafuso tenda, o fechamento primário da ferida com liberação de periósteo sem tensão foi obtido, após 14 dias a membrana estava exposta, no entanto, havia evidências de uma vedação epitelial no local envolvido, sem desprender à sondagem ou supuração. $O$ problema foi resolvido com a continuação dos enxaguatórios bucais com clorexidina $(0,12 \%)$, aplicando gel de clorexidina com concentração de $1 \%$ duas vezes ao dia até o procedimento de reabertura e removendo qualquer placa uma vez por semana no consultório onde acompanhou por 4 meses até a retirada obtendo o preenchimento do defeito Vertical da região de exodontia de pré-molar e primeiro molar superior. Quando o local foi reaberto, o defeito original parecia ter sido preenchido, então dois implantes (CLC Conic; CLC Scientific, Vicenza, Itália), respectivamente de tamanho $4 \times 10 \mathrm{~mm}$ e $5 \times 6 \mathrm{~mm}$, foram inseridos nas posições do primeiro pré-molar e posição do molar. Observaram que devido as membranas de dPTFE não absorvíveis apresentarem poros com 0,2 $\mu \mathrm{m}$ de diâmetro, evitam a infiltração bacteriana e, mesmo que a membrana seja exposta, o risco de complicações e infecções é muito menor do que nas membranas de e-PTFE. Isso torna importante o fechamento primário dos tecidos moles, mas não é estritamente necessário, porque a membrana funciona como uma barreira impenetrável para alimentos e bactérias e concluiu que a exposição da membrana de d-PTFE pode ser gerenciada com um profundo conhecimento dos materiais envolvidos e uma higiene bucal adequada.

Cucchi et al. (2017) avaliaram as taxas de complicação e o ganho ósseo vertical após ROG com membrana Cytoplast $\AA^{\circledR}$ Ti-250 reforçada com titânio comparadas a malha de titânio cobertas por membrana absorvível de colágeno. Comparou o ganho ósseo vertical e as complicações após ROG em mandíbulas posteriores atróficas com Membrana Cytoplast ${ }^{\circledR}$ Ti-250XL e malha de titânio de mandíbulas posteriores, com 
colocação de implantes em 1 estágio, analisou 39 pacientes parcialmente desdentados com mandíbula posterior atrófica divididos aleatoriamente em dois grupos de estudo: 20 pacientes foram tratados com ROG de um estágio, ou seja com colocação de implante simultaneamente, utilizou perfurações corticais para permitir a angiogênese e uma mistura de osso autógeno e aloenxerto (EnCore®), Osteogenics, Biomedical, Lubbock, Texas, somente neste momento foi dado ao cirurgião a membrana a ser utilizada randomicamente, d-PTFE (Grupo A) e malha de titânio coberta por membranas de colágeno reticuladas (Grupo B), 19 pacientes, inicialmente eram 40 mas 1 paciente deste grupo se evadiu, foram fixadas com mini parafusos e fechamento primário da ferida sem tensão com dupla sutura horizontal e vertical. Todas as complicações foram registradas, distinguindo entre "cirúrgico" e "cicatrizante" e entre "menor" ou "maior". Também foram avaliadas a estabilidade primária dos implantes e o ganho ósseo vertical. Obtendo como resultados: No grupo A, as taxas de complicações cirúrgicas, nesses casos, parestesia temporária do nervo mentual e de cicatrização foram de 5,0\% e 15,0\%, respectivamente, No grupo B, as taxas de complicações cirúrgicas e de cicatrização foram de 15,8\% e 21,1\%, respectivamente, foram acompanhados por 9 meses até a remoção das membranas. O ganho ósseo foi aferido com sonda periodontal com divisões de $1 \mathrm{~mm}$ e grau de precisão da medição de $0,5 \mathrm{~mm}$ que foram medidos do ombro do implante até o osso, antes do preenchimento com biomaterial por bucal, lingual, mesial e distal, em cada implante e após a regeneração foram feitas novas medidas. E concluíram que os resultados preliminares deste estudo randomizado controlado mostraram que membranas de d-PTFE e malhas de titânio coberta por membrana de colágeno produziram resultados similares tanto em taxa quanto em tipos em termos de complicações de cicatrização. Em contraste, membranas de d-PTFE mostraram uma taxa média menor de complicações cirúrgicas. Foram conseguidos ganho ósseo vertical e formação óssea similares em ambos os grupos.

Herzberg (2017) descreveu 10 casos de aumento ósseo vertical de rebordo alveolar em região de um dente, por ser uma área crítica devido aos dentes adjacentes à região enxertada, o retalho pequeno, ser mais difícil de adaptar ao aumento 3D conseguido. Fez incisão intrasulcular estendendo até dois dentes adjacentes e passando pela 
crista e relaxante mesial de $10 \mathrm{~mm}$, exceto quando o aumento era anterior então a relaxante foi executada na posterior da incisão. Instalou um implante em sete pacientes e três já tinham implantes, e enxertou com mistura 1:1 de osso autógeno com aloenxerto (Raptos ${ }^{\circledR}$, Citagenix) e cobriu com membrana de d-PTFE reforçada (Cytoplast $\circledast$ Ti-250AS, Osteogenics) cortando e adaptando, e fixando com parafusos auto rosqueantes (Pro-Fix PFMF®, Osteogenics) e uma membrana de colágeno (Remaix®) foi colocada sobre a membrana de d-PTFE e fez fechamento da ferida sem tensão. Após 6 meses não houve exposição da membrana de d-PTFE então removeu a membrana e dos 10 pacientes um perdeu o enxerto, dois perderam 0,5 $\mathrm{mm}$ e um perdeu $1 \mathrm{~mm}$, os demais tiveram sucesso com nenhuma perda. Observou que esta técnica é confiável e em suas referências menciona que é comum perda óssea fisiológica de 0,47 a 1,16 mm durante primeiro ano com procedimento vertical de GBR usando membranas PFTE pode ser atribuído à reabsorção de osso imaturo na parte mais coronal do osso regenerado preferindo a colocação do implante em uma segunda cirurgia para que isso possa ser corrigido neste segundo momento. Também atribui a taxa de sucesso ao fechamento da ferida cirúrgica que em casos de pequenas regiões oferece retalho menor, mais difícil de se adaptar ao ambiente aumentado. Concluiu que ROG vertical em região de 1 elemento dentário, utilizando membrana Cytoplast, é um tratamento confiável.

Hassan et al. (2017) em seu estudo randomizado de boca dividida compararam a membrana de âmnio/cório humano (MAC) com a membrana Cytoplast® de 22 alvéolos de exodontias de 9 participantes nos aspectos: quantidade de preservação das dimensões do cume alveolar, seguindo os procedimentos de preservação do cume, isto é, alteração vertical da altura do cume em milímetros, para isso construíram um stent radiográfico com plano de referência radiopaco com 5 orifícios que pode ser usado com sonda milimétrica e medição na tomografia foram feitas medições por um profissional que desconhecia o objetivo do estudo após as exodontias e 3,5 meses após a exodontia e os dados foram utilizados para análise estatística. Avaliou também qualidade óssea coletando amostras de osso regenerado para análise histológica e histomorfométrica e desconforto através de escala VAS. A Randomização foi feita em mesmo lado ou direito e esquerdo. Obtiveram como resultados: Aumento médio 
horizontal de $2,54(1,29)$ e $2,72(1,01)$ para MAC e Cytoplast ${ }^{\circledR}$ respectivamente seguindo com aumento médio vertical de: $-0,24(0,91)$ e 1,18 $(2,22)$ para Cytoplast. Concluiu que a área óssea mineralizada e a área de tecidos moles não foram significativamente diferentes entre os dois tratamentos. Os locais da MAC apresentaram escores VAS pós-operatórios significativamente mais baixos em comparação com o d-PTFE. O MAC exposto intencionalmente é igualmente eficaz na preservação da crista em comparação com o d-PTFE. Além disso, o uso de MAC pode ajudar a reduzir os escores de VAS no pós-operatório e potencialmente resultar em melhor qualidade de osso disponível para colocação do implante, como evidenciado por medidas histomorfométricas aprimoradas.

Trobos et al. (2018) em seu trabalho com culturas in vitro, avaliaram a função de barreira das membranas Cytoplast ${ }$ TXT200 d-PTFE e NeoGen® e-PTFE contra bactérias de $2 \mathrm{~h}, 12 \mathrm{~h}$ e $48 \mathrm{~h}$. Seu experimento utilizou tubos que tiveram membranas adaptadas que permitiram o contato de um sobrenadante estéril com a superfície interna da membrana e uma cultura de $S$. oralis em contato com a superfície externa e ao analisar o sobrenadante em meio de cultura ágar sangue de cavalo. Coletando material do interior da membrana após $48 \mathrm{~h}$ de experimento a $37^{\circ} \mathrm{C}$ em condição de anaerobiose e não haviam bactérias nem no interior das membranas nem no sobrenadante em contato com as membranas. No entanto, o d-PTFE favoreceu a formação de mais biofilme de $S$. oralis em relação ao titânio e e-PTFE após lavagem com soro, externamente. Concluíram que todas as membranas de PTFE foram barreiras eficazes contra a passagem bacteriana in vitro.

Gallo; Díaz-Báez (2019) com o propósito de descrever o manejo de complicações como exposições e infecções após ROG vertical e horizontal com membrana Cytoplast ${ }^{\circledR}$. Utilizando um novo protocolo de manejo de complicações relatado para este tipo de membrana. Para isso avaliaram as complicações na regeneração óssea executada com membrana de d-PTFE reforçada com titânio Cytoplast Ti-250, Osteogenics Biomedical entre 2000 e 2017 de 80 casos que tiveram complicações e tratou casos de exposição da membrana menor ou igual a $3 \mathrm{~mm}$ sem infecção e após 2 meses da cirurgia mantendo por 9 meses monitorando a higiene do paciente 
semanalmente limpando com clorexidina e recomendando da leve escovação da membrana e aplicação de clorexidina em gel para prevenir acumulo de placa, quando a exposição apareceu antes disso foi mantida a membrana por 6 a 8 semanas, seguindo o mesmo protocolo de higiene e depois disso removida. Quando houve relado de dor e pus, optou por remover imediatamente e curetar o tecido granulomatoso e manter o tecido duro, os pacientes foram medicados com (amoxicilina/ac. Clavulânico $1 \mathrm{~g}$ de 12/12h). O sextante com maior número de complicações foi a maxila anterior (43,75\%), seguida de mandíbula esquerda $(20 \%)$. $70 \%$ dos casos apareceu após 2 meses. Concluiu que este protocolo de manejo de complicações que foi proposto baseado nas 80 complicações, pode ajudar a prevenir a perda de todo o enxerto e que infecção é a principal complicação que causa perda do enxerto. Concluiu que este novo protocolo de manejo de complicações de ROG proposto, baseado nas 80 complicações observadas, pode ajudar a prevenir a total perda do enxerto.

Koidou; Chatzopoulos; Johnson (2019) relataram, uma série de casos onde utilizou uma membrana de colágeno reticulado sobre o aloencherto e sobre o conjunto fixou uma membrana de d-PTFE, a qual ficou por 6 semanas e foi removida atraumaticamente encontrando quando a membrana do d-PTFE foi removida, tecido conjuntivo imaturo e foi observado que se tornou gengiva queratinizada 8 semanas após a extração e concluíram que o uso de uma membrana de d-PTFE sobre uma membrana de colágeno nas cavidades pós-extração evita a degradação precoce da membrana absorvível e preserva sua integridade.

Cucchi et al. (2019) compararam os resultados de ROG entre membrana Cytoplast $\AA$ e Malha de titânio coberta por membrana Osseoguard® fez um estudo duplo cego que comparou os resultados histológicos e histomorfométricos do tecido ósseo retirado da região enxertada de mandíbulas posteriores com a mistura de 1:1 de osso autógeno e aloenxerto (EnCore® Osteogenics Biomedical),fez decorticalização, utilizando no grupo A 13 pacientes com membrana de d-PTFE Cytoplast $\AA^{\circledR}$ Ti-250 XL e no grupo B, 12 pacientes com malha de Titânio Trinon Titanium $\circledast$, Karlshure, Germany coberta com membrana de colágeno e fixou com dois ou três mini parafusos ProFix®. Suturou 
com dupla camada horizontal e simples, obteve fechamento primário, aguardou 9 meses. Não houve exposição as amostras foram fixadas em fosfato-buferinado formalina seguido de descalcificação ácido Hidroclorídrico e ácido Fórmico, após descalcificação as amostras foram desidratadas em séries de banhos de álcoois graduados e embebidas em parafina, então as secções histológicas foram coradas com hematoxilina e eosina. As lâminas foram escaneadas (ScanScope CS $\AA$, Aperio Tecnologies, Leica Biosystems) em várias magnificações para avaliar as características do novo osso formado, do material de enxerto remanescente, a integração do material enxertado com o novo osso formado, tecido mole e inflamação local. A regeneração óssea na porção coronal foi evidente em ambos os grupos, e havia intimo contato entre o material enxertado e o osso, ativa formação óssea foi encontrada foi aparente em todas as regiões de osso enxertado refletida por altas densidades de osteócitos e trabeculado neoformado, associado a intensa atividade de osteoblastos nas frentes de crescimento ósseo. Reabsorções mediadas por osteoclastos foram detectadas próximos ao material de enxerto, todas as biópsias continham células de tecido conectivo com muitas veias. Os enxertos estavam justapostos em todas as amostras e não havia processos inflamatórios ou reações imunológicas nos locais regenerados. Os dados histomorfométricos demonstraram ambas as membranas preveniram a migração de células não osteogênicas. $\mathrm{N}$ grupo A as proporções de tecido ósseo, material de enxerto e tecido mole foi $39,7 \% ; 8,6 \%$; $52,1 \%$ e no grupo B 42,1\%; 9,6 e 48,3\%, não encontrou diferença significante entre os grupos. Concluiu que os resultados do estudo sugeriram que ROG utilizando membrana de d-PTFE Cytoplast $\AA$ ou malha de Ti Trinon Titanium $\AA$ em combinação com osso autógeno e aloenxerto proporcionam resultados similares tanto histologicamente como hitomorfometricamente.

Mertens et al. (2019) testaram 4 técnicas diferentes in-vitro quanto a estabilidade do volume num defeito de rebordo de uma parede. Grupo 1: ROG com membrana de colágeno, xenoenxerto particulado, Grupo 2: ROG com membrana de colágeno, xenoenxerto particulado e tachas, Grupo 3: ROG com membrana reforçada com Titânio Cytoplast $\circledast$ Ti-250, xenoenxerto particulado e pinos, Grupo 4 ROG com bloco autógeno, membrana de colágeno, xenoenxerto particulado, registrou com 
tomografias e testou. Para isso criou os defeitos em mandíbulas de porcos e executou os procedimentos até o fechamento do retalho depois ele desmontava e fazia as medições: antes e depois da sutura, e calculava a mudança em $\mathrm{mm}$ e percentual e encontrou como resultados que nos 4 grupos o fechamento do retalho conduziu a uma redução de volume, grupos 2, 3, 4 tiveram melhores resultados que o grupo 1: colágeno sem pino. Os grupos 3 e 4 melhores que o grupo 2: colágeno e pino e grupo:3 d-PTFE melhor resultado que grupo 4.Concluíram que fechamento do retalho tem influência significante na estabilidade do enxerto em defeitos de 1 parede, a fixação adicional com pinos melhora a estabilidade da Membrana de Ti-d-PTFE e enxerto em bloco mostraram maior estabilidade que as membranas de colágeno, especialmente na região do ombro do implante e que defeitos de uma parede a estabilização do enxerto é ainda de maior importância que nos defeitos de auto contentores.

Ibraheem et al. (2020), acompanharam RGB com membrana Cytoplast $\AA$ com uma exposição que se desenvolveu durante o período de ossificação do enxerto. E para isso relatou um caso de aumento ósseo com colocação simultânea de três implantes na região dos dentes $35,36,37$, utilizando membrana de d-PTFE Cytoplast $\Theta$, associada a aloencherto ósseo LifeNet@ Health, Virginia Beach, VA, em volta das espiras expostas 3-4,5 $\mathrm{mm}$ do lado bucal e depois completou com uma camada de BioOss $\AA$, e depois que fixou a membrana de d-PTFE com mini parafusos ProFix $\AA_{\text {. }}$. Após 21 dias foi retirada a sutura e havia exposição de $3 \mathrm{~mm}$ da membrana, paciente foi orientada a passar Polvidine $\AA^{\circledR}$ duas vezes ao dia com um algodão a exposição continuou aumentando evoluindo para uma deiscência severa na $16^{\circ}$ semana, mas as bordas da membrana não foram expostas, não havia evidências de infecção, a membrana foi removida revelando tecido fibroso cobrindo os implantes. 10 semanas após a remoção da membrana foi feita reabertura e havia osso regenerado cobrindo os parafusos de cobertura. Um núcleo foi retirado com trefina para análise histológica e preparadas lâminas de coloração hematoxilina/eosina, e revelou Osso viável denso e em volta do osso o material de aloencherto integrado. Concluíram que a membrana Cytoplast ${ }^{\circledR}$, quando exposta, não necessariamente conduz ao insucesso se manejada apropriadamente com intervalos curtos de follow-up. 
Mazzucchi et al., (2020) compararam amostras da parte superior e da parte inferior da membrana de d-PTFE com relação as contagens bacterianas das duas superfícies após 28 dias de preservação de alvéolo de exodontias com exposição ao meio bucal. As análises microbiológicas e microscópicas revelaram que uma quantidade de bactérias estava presente na camada interna, por baixo da tecidos gengivais perialveolares. Esse achado sugeriu que bactérias poderiam migrar pela gengiva aderida a membrana e colonizar a parte interna da membrana, encontrando um caminho entre a camada externa e os tecidos gengivais que não aderiram à superfície lisa da membrana de d-PTFE. Outra possibilidade é que a colonização ocorra durante os procedimentos cirúrgicos: no entanto, nas duas circunstâncias, isso não afetou o processo de cicatrização, provavelmente devido ao pequeno número de bactérias presentes no local.

\section{DISCUSSÃO}

Barber et al., (2007) e Ghensi et al., (2017) relataram casos de ROG de alvéolos de exodontias que receberam biomaterial e foi utilizada a membrana de d-PTFE Cytoplast $\circledast$ como barreira. Barber et al. (2007), não obteve intencionalmente o fechamento primário da ferida, que foi descrito por WANG et al. em 2006 como princípio do PASS, alegando ser desnecessário devido a densidade da membrana dPTFE impedir a contaminação do biomaterial abaixo da membrana e manteve por 6 semanas a membrana exposta ao meio bucal com acompanhamento da higiene e concluiu que o fechamento primário da ferida é desnecessário em sua discussão ele comentou que ele e sua equipe não tinham experiência suficiente para comentar sobre a eficácia de manter a membrana exposta por mais que 6 semanas. Já Ghensi et al., (2017) exatamente 10 anos depois, em seu relato, apesar de ter feito dupla sutura e ter obtido inicialmente o fechamento primário da ferida, relatou uma exposição da membrana onde acompanhou por 4 meses. Ambos obtiveram sucesso com a ROG, confirmando que não houve contaminação do enxerto. E Ibraheem et al., (2020) observou uma exposição em aumento vertical por 4 meses, e obteve ROG, neste relato de caso a Membrana Cytoplast Ti-250 foi fixada com parafusos. 
Koidou et al. (2019) em sua série de casos obteve ROG, utilizando A membrana Cytoplast $\circledast$ e uma membrana de colágeno entre o enxerto e a membrana, deixando a membrana exposta intencionalmente. Hertzberg (2017) em sua série de casos obteve ROG utilizando a membrana Cytoplast Ti-250 e uma membrana de colágeno por cima da membrana de d-PTFE que foi fixada com pinos de titânio e fechamento primário da ferida foi obtido.

Hassan et al., (2017) se utilizou de um modelo de estudo comparativo randomizado de boca-dividida que diminui o viés porque é possível minimizar as variáveis interindividuais, uma vez que os sujeitos participantes servem como seus próprios controles e, quando presentes, interferem de igual forma nos tratamentos. As membranas eram Cytoplast ${ }^{\circledR}$ e MAC, Obteve ROG mantendo as membranas expostas ao meio bucal por 3,5 meses apesar de não ter obtido como resultado primário que a membrana Cytoplast $\circledast$ resistiu a penetração bacteriana mencionou em sua conclusão que o MAC exposto intencionalmente é igualmente eficaz na preservação da crista em comparação com o d-PTFE e Hoffmann et al., (2008) em seu estudo retrospectivo longitudinal, executou ROG em 276 alvéolos de exodontias que devido à relativamente elevada população inscrita, reproduz forte relação temporal de casualidade. Alguns detalhes do estudo merecem ser destacados: primeiramente o mascaramento e calibragem do examinador que mediu os defeitos e depois a regeneração, e padronizou as medidas com casquetes individuais permitindo 5 medições mapeando cada defeito, que aumenta a confiabilidade dos resultados. Ao analisar os dados as variáveis descrevendo a Perda óssea foram reportadas individualmente por todos os casos envolvidos e também separadamente em braços por fatores de interesse investigados que foram: formato do alvéolo, maxilar superior ou inferior e região e o Ganho ósseo vertical foi expresso em médias \pm (DP) e mínimo, máximo e valores médios. $\mathrm{E}$ amostras independentes para teste foram usadas para detectar algum efeito relacionado ao sexo ou fumar na perda óssea e utilizou correlação de Pearson para investigar influência de idade em ganho ósseo. Não encontrou nenhuma influência das variáveis mencionadas acima. Fez mensurações de ganho ósseo tridimensional, obtendo uma média de ganho ósseo vertical de $6 \mathrm{~mm}$, e ainda coletou amostras que demonstraram que houve regeneração óssea em 
análise histológica. Na descrição da técnica ele ressaltou que o fechamento primário da ferida não foi obtido, a remoção da membrana foi feita após 4 meses, ambos os autores mantiveram as membranas expostas inclusive MAC por um período entre 3,5 e 4 meses.

Dois experimentos levantaram evidencias relevantes sobre as características de impermeabilidade e capacidade de integração aos tecidos da membrana Cytoplast $\Theta_{\text {. }}$. Trobos et al., (2018) ao testar a membrana de d-PTFE em seu experimento in-vitro com cultura de S.oralis 2,12,24 e 48hs, concluiu que ela é impermeável a bactérias já Mazzucchi, et al., (2020) analisou membranas retiradas de pacientes vivos e encontrou bacterias na parte inferior da membrana em pequena quantidade mas não prejudicaram os enxertos, ela argumentou que poderiam ter penetrado pelas bordas devido a pouca integração dos tecidos ou durante a cirurgia.

Gallo et al. (2019) ao analisar as complicações em seu estudo de 80 casos, relatou exposições da membrana Cytoplast $\AA$, as quais acompanhou por 9 meses orientando e acompanhando os pacientes quanto a higiene e o uso de clorexidina $0,2 \%$ até a cura. Propondo um protocolo de manejo de exposições da membrana de d-PTFE ao meio bucal, confirmou a resistência à penetração bacteriana, corroborando com os resultados e recomendações de Ibraheem et al., (2020).

Ibraheem (2020) em seu relato de caso fez uma ROG em região de 3 elementos, e acompanhou uma exposição $>3 \mathrm{~mm}$ por 10 meses e concluiu que a membrana Cytoplast ${ }^{\circledR}$, quando exposta, não necessariamente conduz ao insucesso se manejada apropriadamente com intervalos curtos de follow-up, que confirma que a membrana de d-PTFE Cytoplast ${ }^{\circledR}$ resiste a penetração bacteriana corroborando com Maridati, et al., (2016) que teve exposição da membrana e acompanhou por 4 meses e ao retirar a membrana, também obteve ROG, este último autor não mencionou utilização de antisséptico mas a utilização de um antisséptico tópico parece ter um papel importante no prognóstico de exposições para Gallo (2019) e Ibraheem (2020).

Urban et al., (2014), em sua pesquisa, ao fixar a membrana reforçada de Ti-d-PTFE Cytoplast ${ }^{\circledR}$ Ti 200 com tachas Master Pin Control®, Messinger e/ou parafusos tenda 
Pro-Fix Tentin Screw®, Osteogenics Biomedical, criou o andaime necessário a criação de espaço. Ao executar perfurações corticais, a liberação do retalho e ao obter fechamento do retalho sem tensão com sutura dupla de colchoeiro horizontal e simples, não tendo havido exposição da membrana por 9 meses, atendeu aos seguintes princípios do PAEE de Wang, (2006): (i) fechamento primário da ferida, (ii) angiogênese e (iii) criação de espaço. Ao encontrar resultado de ganho ósseo de 5,45 mm com 1,93 de desvio padrão confirmou que a capacidade de criar e manter espaço e de estabilização da ferida foram atendidas pois se a membrana de d-PTFE Cytoplast ${ }^{\circledR}$ não tivesse a capacidade de criar e manter espaço e estabilizar a ferida em aumentos ósseos verticais, não teria atingido os aumentos ósseos obtidos pelos autores, considerando que a angiogênese e fechamento primário foram conseguidos quando descreveram que não houve exposição da membrana já Mertens et al., (2019) observaram em seu estudo com mandíbulas de suínos que o ato de fechar os retalhos sem tensão com dupla sutura, causou diminuição do volume vertical do enxerto particulado e ainda observou que o uso de Tachas reduziu a deformação do enxerto particulado e Herzberg et al., (2017) reconheceram que muitas vezes o fechamento primário da ferida é difícil de ser obtido como por exemplo em regiões de um dente.

Ronda et al., (2014) obtiveram resultados semelhantes com duas membranas diferentes Ti-d-PTFE e Ti-e-PTFE em ROG, 116.8\% e 119.7\%, não houve exposição das membranas, os implantes foram instalados simultaneamente com a ROG em 1 estágio e foi feita decorticalização. É possível perceber que todos os princípios do PAEE foram preenchidos neste estudo e Cucchi, (2017) em seu estudo comparativo entre membrana Cytoplast $\circledast$ de Ti-d-PTFE reforçada e malha de titânio coberta com membrana de colágeno para ROG de mandíbulas posteriores e colocação de implantes de 1 estágio, obteve resultados semelhantes em ganho ósseo. Ainda Cucchi, (2019) dando continuidade ao trabalho de 2017 com as análises histológica e histomorfométrica apresentaram regeneração óssea evidente nas partes coronais de ambos os grupos e íntimo contato entre material de enxerto osso e o enxerto serviu de ponte para o osso neoformado, determinando que houve regeneração óssea ambos os estudos randomizados e mascarados tanto na distribuição de pacientes como nas obtenções das medidas. 
Oliveira (2015) em seu artigo sobre Relatos e séries de casos observou que apesar de sua importância, os relatos e séries de casos têm risco de viés e que normalmente publicam casos de sucesso. Por terem baixo risco de viés, os ensaios randomizados a seguir: Ronda (2013) e Cucchi (2017), foram selecionados para serem agrupados em um gráfico "Forest Plot". Iportante ressaltar que, para que pudessem ter sido publicados no periódico Clínical Oral Implant Research, conforme consulta realizada na página de submissão da revista, segue o trecho: "Ensaios clínicos randomizados devem ser relatados utilizando as diretrizes do CONSORT. Uma lista de verificação CONSORT 2010 também deve ser incluída no material de submissão" (AUTHOR GUIDELINES, acesso em: 15/09/2020), portanto, uma vez que atendem as diretrizes de ensaios randomizados, tendo preenchido os requisitos da lista de verificação, podem ser considerados padrão ouro. Foram agrupados em um gráfico "Forest plot" obtido com a utilização do software Review Manager 5.4 que pôde ser realizado devido à baixa heterogeneidade entre os estudos e resultados quantitativos de ganho ósseo em mm, que pôde ser observada pelo teste $\mathrm{x}^{2}$ e $\mathrm{l}^{2}$ apresentados nas legendas com resultados 0,55 e $0 \%$ respectivamente, que sugeriu que fosse utilizado o modelo de análise de efeito fixo. Apenas confirma as conclusões dos autores, mas demonstra um padrão tendendo a favorecer a membrana Cytoplast ${ }^{\circledR}$ em relação a tela de titânio e membrana de e-PTFE em ganho ósseo / entenda-se como capacidade de criação e manutenção de espaço também devido ao enxerto depender completamente da membrana para se manterem posição, por exemplo se os estudos tivessem o dobro do total de intervenções já movimentaria o losango preto para fora do eixo 0 , o que também propõe a realização de estudos como estes com uma amostragem mínima de duas vezes maior. Foi utilizado o software Review Manager 5.4 para configuração da meta-análise e simulações. 
Figura 1. Forest Plot Ganho médio ósseo d-PTFE x Controle

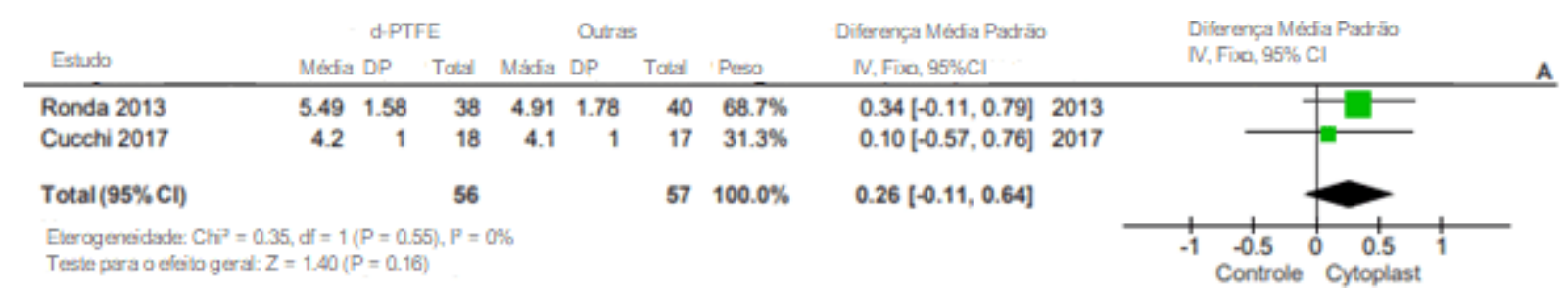

Software utilizado Review Manager 5.4 pelo autor em (2020) Heterogeneidade: $\mathrm{Chi}^{2}=0,35, \mathrm{df}=1 \quad(\mathrm{P}=0,55) ; \mathrm{I}^{2}=0 \%$ Teste para o efeito geral: $Z=1,40(P=0,16)$

A maneira como o Review Manager 5.4 executou os cálculos foi descrita por Deeks e Higgins, (2010). Os tipos dos dados que foi encontrado nos resultados dos ensaios clínicos randomizados foram contínuos, o método de análise escolhido foi de variância inversa de efeito fixo e a medida do efeito em diferença média padrão e os intervalos de confiança de $95 \%$.

Analisando os relatos e séries de caso onde optaram-se por experimentar deixar a membrana exposta intencionalmente, baseados na característica de impermeabilidade à bactérias e integração dos tecidos à membrana e que obtiveram regeneração óssea e ganho ósseo tanto em altura como em largura e ainda alguns comprovaram por análises histológicas e histomorfométricas, ainda restou uma lacuna sobre a qualidade da integração da membrana de d-PTFE Cytoplast $\AA^{\circledR}$ aos tecidos, se é completa o suficiente para impedir que o retalho da mucosa não permita passagem de bactérias nos casos de exposição, o uso de Clorexidina em gel tópico e remoção mecânica de placa bacteriana na parte superior da membrana são essenciais no controle de exposições e controle periodontal prévio e posterior à intervenção cirúrgica são práticas que podem minimizar este risco. Observou-se que existem evidências e que necessitam modelos de estudos com esta membrana que explorem estas propriedades. 


\section{CONCLUSÃO}

Após termos analisado os trabalhos científicos desta revisão, concluímos que a membrana de d-PTFE Cytoplast $\AA$ atende às necessidades de uma membrana para preservação e aumento de rebordo alveolar, permitindo um período de exposição à cavidade oral, sem que haja infiltração de microrganismos na região enxertada desde que o paciente seja acompanhado por rígido protocolo de higiene e as bordas da membrana estejam cobertas por tecido e nos casos de aumento vertical quando reforçada com titânio e fixa por tachas ou parafusos, Cytoplast Ti-250 é capaz de criar e manter espaço para que haja ROG quando obtido fechamento da ferida primário sem tensão feito com manobra de incisão de liberação do periósteo.

\section{REFERÊNCIAS}

BARTEE, Chaddick M.; BARTEE, Barry K.. Hydrophilic high density PTFE medical barrier. Depositante: Chaddick M. Bartee, Barry K. Bartee. US7296998B2. Depósito: 21 set 2007.

BARBER, Dexter H.; LIGNELLI, John; SMITH, Brian M.; BARTEE, Barry K. Using a Dense PTFE Membrane Without Primary Closure to Achieve Bone and Tissue Regeneration. Journal of Oral and Maxillofacial Surgery, Estados Unidos, v. 65, n. 4, p. 748-752, abr. 2007. ISSN: 0278-2391. DOI: 10.1016/j.joms.2006.10.042.

CUCCHI, Alessandro; VIGNUDELLI, Elisabeta; NAPOLITANO, Aldo; MARCHETTI, Claudio; CORINALDESI, Giuseppe. Evaluation of complication rates and vertical bone gain after guided bone regeneration with non-resorbable membranes versus titanium meshes and resorbable membranes. A randomized clinical trial. Clinical implant dentistry and related research, Estados Unidos, v. 19, n. 5, p. 821-832, out. 2017. ISSN: 1523-0899. DOI: 10.1111/cid.12520.

CUCCHI, Alessandro; SARTORI, Maria, PARRILLI, Annapaola; ALDINI, Nicolò N.; VIGNUDELLI, Elisabetta; CORINALDESI, Giuseppe. Histological and histomorphometric analysis of bone tissue after guided bone regeneration with non- 
resorbable membranes vs resorbable membranes and titanium mesh.(Report). Clinical Implant Dentistry and Related Research, Estados Unidos, v. 21, n. 4, p. 693, ago. 2019. ISSN: 1523-0899. DOI: 10.1111/cid.12814.

DEEKS, Johnathan J.; HIGGINS, Julian P. T. Statistical algorithms in Review Manager 5: on behalf of the Statistical Methods Group of The Cochrane Collaboration, Cochrane Collaboration. p. 1-11, ago. 2010. Disponível em https://training.cochrane.org/handbook/statistical-methods-revman5. Acesso em: 08/07/2020.

GALLO, Pier; DÍAZ-BÁEZ, David. Management of 80 Complications in Vertical and Horizontal Ridge Augmentation with Nonresorbable Membrane (d-PTFE): A CrossSectional Study. The International journal of oral \& maxillofacial implants, Estados Unidos, v. 34, n. 4, p. 927-935, jul. 2019. ISSN: 0882-2786. DOI: 10.11607/jomi.7214.

GHENSI, P;STABLUM, W; BETTIO, E; SOLDINI, M. C.;TRIPI,T. R.;SOLDINI, C. Menagemente of the exposure of a dense PTFE (d-PTFE) membrane in guided bone regeneration (GBR): A case report. Oral \& Implantology, Itália, v. 10, n. 3, p. 335, jul. 2017. ISSN: 1974-5648. DOI: 10.11138/orl/2017.10.3.335.

HASSAN, Muyeenul M.; PRAKASAM, Sivaraman; BAIN, Carol; GHONEIMA, Ahmed; LIU Sean Shih-Yao. A Randomized Split-Mouth Clinical Trial on Effectiveness of Amnion-Chorion Membranes in Alveolar Ridge Preservation: A Clinical, Radiologic, and Morphometric Study. The International Journal of Oral \& Maxillofacial Implants, Estados Unidos, v. 32, n. 6, p. 1389-1398, nov. 2017. ISSN: 0882-2786. DOI: 10.11607/jomi.5875.

HERZBERG, RAN. Vertical Guided Bone Regeneration for a Single Missing Tooth Span with Titanium-Reinforced d-PTFE Membranes: Clinical Considerations and Observations of 10 Consecutive Cases with up to 36 Months Follow-up. The International journal of periodontics \& restorative dentistry, Estados Unidos, v. 37, n. 6, p. 893-899, nov. 2017. ISSN: 0198-7569. DOI: 10.11607/prd.3380. 
HOFFMANN, Oliver.; BARTEE, Barry K.; BEAUMONT, Christian; KASAJ, Adrian;DELI, Giorgio; ZAFIROPOULOS, Gregor Georg. Alveolar bone preservation in extraction sockets using non-resorbable dPTFE membranes: a retrospective nonrandomized study. Journal of periodontology, Estados Unidos, v. 79, n. 8, p. 135569, ago. 2008. ISSN: 0022-3492. DOI: 10.1902/jop.2008.070502.

IBRAHEEM, Ahmed Gamil; BLANCHARD, Steven B. Alveolar ridge augmentation around exposed mandibular dental implant with histomorphometric analysis. Clinical advances in periodontics, Estados Unidos, jan. 2020. ISSN: 2163-0097. DOI: 10.1002/cap.10090. https://aap.onlinelibrary.wiley.com/doi/epdf/10.1002/cap.10090. Acesso em: 15/09/2020.

KOIDOU, Vasiliki P.; CHATZOPOULOS, Georgios S.; JOHNSON, Deborah. The "Combo Technique": A Case Series Introducing the Use of a d-PTFE Membrane in Immediate Postextraction Guided Bone Regeneration. J Oral Implantol., Estados Unidos, v. 45, n. 6 p. 486-493, dez. 2019.ISSN: 0160-6972. DOI: 10.1563/aaid-joi-D19-00015.

LEE, Jun-Beom; LEE, Jung-Tae; HWANG, Sukhiun; CHOI, Jung-Yoo; YEO, In-Sung L. Leukocyte- and platelet-rich fibrin is an effective membrane for lateral ridge augmentation: An in vivo study using a canine model with surgically created defects. Journal of periodontology, Estados Unidos, v. 91, n. 1, p. 120-128, jan. 2020. ISSN: 0022-3492. DOI: 10.1002/JPER.19-0186.

MARIDATI, Paolo. C.;CREMONESI, Sergio; FONTANA, Filippo; CICCIÙ, Marco; MAIORANA, Carlo. Management of d-PTFE Membrane Exposure for Having Final Clinical Success. The Journal of oral implantology, Estados Unidos, v. 42, n. 3, p. 289-291, jun. 2016. ISSN: 0160-6972. DOI: 10.1563/aaid-joi-D-15-00074.

MAZZUCCHI, Giulia; LOLLOBRIGIDA, Marco; LAURITO, Domenica; DI NARDO, Dario; BERLUTTI, Francesca; PASSARIELLO, Claudio; SERAFINI, Giorgio; TESTARELLI, Luca; DE BIASE, Alberto G. Microbiological and FE-SEM Assessment 
of d-PTFE Membrane Exposed to Oral Environment after Alveolar Socket Preservation Managed with Granular nc-HA. The journal of contemporary dental practice, India, v. 21 , n. 4 , p. $404-409,1$ abr. 2020. ISSN: 1526-3711.

MERTENS, Christian; SEBASTIAN Braun; KRISAM, Johannes; HOFFMANN, Jürgen. The influence of wound closure on graft stability: An in vitro comparison of different bone grafting techniques for the treatment of one-wall horizontal bone defects. Clinical implant dentistry and related research, Estados Unidos. v. 21, n. 2, p. 284-291, 11 abr. 2019. ISSN: 1523-0899. DOI: 10.1111/cid.12728.

NAUNG, Noel. Ye.; SHEHATA, Ehab.; VAN SICKELS, Joseph. E. Resorbable Versus Nonresorbable Membranes: When and Why? Dental Clinics of North America, Estados Unidos v. 63, n. 3, p. 419-431, jul. 2019. ISSN: 0011-8532. DOI: 10.1016/j.cden.2019.02.008.

OLIVEIRA, Marco Aurélio Pinho; VELARDE, Guillermo Coca ; DE SÁ, Renato Augusto Moreira. Understanding the clinical research $\mathrm{V}$ : case report and series of case report. Femina, Brasil, v.43, n 5 p. 235-38, set. 2015. Disponível em: http://files.bvs.br/upload/S/0100-7254/2015/v43n5/a5320.pdf. Acesso em: 05/05/2020. ISSN: 0100-7203

REVIEW MANAGER 5.4 (Rev Man 5). The Cochrane Collaboration, set. 2015. Diponível em: https://training.cochrane.org/online-learning/core-software-cochranereviews/revman/reasons-downloading-revman-5. Acesso em: 05/06/2020.

RONDA, Marco; REBAUDI, Alberto; TORELLI, Lucio; STACCHI, Claudio. Expanded vs. dense polytetrafluoroethylene membranes in vertical ridge augmentation around dental implants: a prospective randomized controlled clinical trial. Clinical oral implants research, Dinamarca, v. 25, n. 7, p. 859-866, jul. 2014. ISSN: 0905-7161. DOI: $10.1111 / \mathrm{clr} .12157$.

SALOMÃO, M.; F.K. ALVAREZ; J.T.T. SIQUEIRA. Guided bone regeneration after tooth extraction using membrane exposed to the oral environment. Case reports. Implantnews, Brasil, v. 7, n 6, p. 753-9. jun. 2010. ISSN: 2358-905. 
SCHULZ, Knneth F.; ALTMANN, Douglas G.; MOHER, David; CONSORT. CONSORT 2010 Statement: updated guidelines for reporting parallel group randomised trials. International journal of surgery, Inglaterra v.9, n. 8, p. 672-677, 2011. ISSN: 17439191. DOI: 10.1016/j.jjsu.2011.09.004.

TROBOS, Margarita; JUHLIN, Annika; SHAH, Furqan A.; HOFFMANN, Maria; SAHLIN, Herman; DAHLIN, Christer. In vitro evaluation of barrier function against oral bacteria of dense and expanded polytetrafluoroethylene (PTFE) membranes for guided bone regeneration. Clinical Implant Dentistry and Related Research, Estados Unidos, v. 20, n. 5, p. 738-748, out. 2018. ISSN: 1523-0899. DOI: 10.1111/cid.12629.

URBAN, Istvan A.; MONJE, Alberto; NEVINS, Myron; NEVINS, Marc L; LOZADA Jamie L; WANG, Hom-Lay. Surgical Management of Significant Maxillary Anterior Vertical Ridge Defects. The International Journal of Periodontics \& Restorative Dentistry, Estados Unidos, v. 36, n. 3, p. 329-337, mai. 2016. ISSN: 0198-7569. DOI: 10.11607/prd.2644.

URBAN, Istvan A.; MONJE, Alberto; LOZADA Jamie L; WANG, Hom-Lay. Principles for Vertical Ridge Augmentation in the Atrophic Posterior Mandible: A Technical Review. The International Journal of Periodontics \& Restorative Dentistry, Estados Unidos, v. 37, n. 5, p. 639-645, set. 2017. ISSN: 0198-7569. DOI: 10.11607/prd.3200.

WANG, Hom. Lay.; BOYAPATI, Lakshmi. "PASS" principles for predictable bone regeneration. Implant Dentistry, Estados Unidos, v. 15, n. 1, p. 8-17, mar. 2006. ISSN: 1056-6163. DOI: 10.1097/01.id.0000204762.39826.0f.

ONLINELIBRARY.WILEY.COM. Author Guidelines: Research Reporting Guidelines. Clinical Oral Implants Research. Dinamarca. Disponível em: https://onlinelibrary.wiley.com/page/journal/16000501/homepage/ForAuthors.html. Acesso em: 15/09/2020. ISSN: 1600-0501

Enviado: Setembro, 2020. 
Aprovado: Setembro, 2020. 